\title{
CONCEPT OF AGING IN UNANI MEDICINE
}

\author{
Malik Itrat*1, Zarnigar $^{2}, \mathrm{~N}$. Haque ${ }^{3}$
}

${ }^{1}$ Lecturer, Dept. of Preventive and Social Medicine, Allama Iqbal Unani Medical College, Muzaffarnagar, U.P., India

${ }^{2}$ Lecturer, Dept. of Preventive and Social Medicine, National institute of Unani Medicine, Bangalore, Karnataka, India

${ }^{3}$ Lecturer, Dept. of Ilmul Advia, Eram Unani Medical College, Lucknow, U.P., India

Received on: 12/01/13 Revised on: 19/02/13 Accepted on: 10/03/13

\author{
*Corresponding author \\ E-mail: malik.itrat@gmail.com \\ DOI: $10.7897 / 2277-4343.04331$ \\ Published by Moksha Publishing House. Website www.mokshaph.com \\ All rights reserved.
}

\section{ABSTRACT}

The process of ageing starts since birth and continues till death. Geriatrics is a new emerging field of medical science concerned with the problems of ageing including physiological, pathological, psychological, economic and sociological problems. According to Unani concept with increasing age, the innate heat and innate moisture reduced gradually that weakens the tabiat ( control all faculties of body and all functions of the body) and slows down the bodily function and processes resulting in decreased production of akhlat saleh and increased production of extraneous moisture i.e. disturbed homeostasis or altered temperament. Extraneous moisture is susceptible for fasad and taffun. In the present paper the concept of aging and principles of geriatric care in Unani system of medicine will be discussed in detail.

Key words: Geriatrics, Tadabeer-e-mashaikh

\section{INTRODUCTION}

Ageing is a process of gradual, progressive and generalized impairment of functions resulting in the loss of adaptive response to stress and in increasing the risk of age-related diseases. The overall effect of these alterations is an increase in the probability of dying, which is evident from the rise in age specially death rates in the population ${ }^{1}$.

According to classical Unani literature the human beings originate from Mani of male (Male sperm), which acts as fa'el, plays the part of factor, and Mani of Female (female ovum) which acts as mafool, provides the matter. Each of these is fluid and moist, but there is more wetness and terrene substance in the female ovum, whereas air and igneity are predominant in male sperm. It is essential that at the outset of the congelations of the two components, there should be moisture; even though earth and fire are found in the product. The earth provides the firmness and rigidity, the fire provides the maturative power. These give the coagulum certain firmness or hardness. Organismal aging is the result of two opposing processes.

- Tahleele ratoobate ghareezia by hararate ghareezia to maintain the organism in functional state

- Inadequate Compensation of tahleel by Quwwate hadima that maintain balance or homeostasis ${ }^{2-5}$

\section{Tahleel (Dissolution)}

The human body is soft and moist and its ratoobat always undergoes tahallul (dissolution). Our bodies are exposed to two types of injuries each having an exterior and interior cause. One of the two kinds of injuries is the tahleele ratoobate ghareezia (dissolution of innate moisture from which we have been created) by hararate ghareezia. It takes place gradually. Tabiyat the resisting force tries to maintain the balance (harmony) by producing the substitute of tahleel via Quwwate hadima. Over a period of time the quantity of ratoobate ghareezia decreases. Due to increased tahleel of ratoobate ghareezia, hararate ghareezia weakens because ratoobate ghareezia provide matter for hararate ghareezia. Quwwate hadima also get weakened due to weakness in hararate ghareezia, ultimately resulting in decreased formation of akhlat and ratoobat, and decreased availability of the substitute of tahleel. Decrease in hararate ghareezia changes the mizaj relatively to barid; gradual increase with age in baroodat results in decline of quwa (faculties) thereby afaal (functions) of the body. As all quwa requires hararat for performing afaal (function). Depravity of humours or dryness continues neutralizing the ratoobat of the body until the form ceases to have a capacity for life.

The second source of injury is taffun (putrefactive breakdown and metamorphosis) of the humors into a form such that fermentative phenomenon of life are no longer able to proceed. Finally, the taffun (putrefactive breakdown) disperses the vitality, because it first destroys the ratoobat (moisture), and then tahleel (dissolve) it, and simply dry ash is left behind. Each of them takes origin from extrinsic and intrinsic agents. The extrinsic agents is, e.g. the atmosphere, which causes tahallul and taaffun in the ratoobat. The intrinsic agents are, e.g. the hararate ghareezia (innate heat), which causes tahleel of the ratoobat (moisture). The hararate ghareebiya (extraneous heat) generated within us from the elements, diet and through other agents which causes taffun (putrefactive changes) in the ratoobat.

All these agents mutually aid one another in rendering the body dry and yet it is true that our perfection and soundness and the power to perform our various actions depend on a due degree of dryness of the body but the degree of dryness becomes relatively greater and greater until we die hence this dryness is inevitable. As the dryness increases, the innate heat diminishes. The loss continues unceasingly till death, and the moisture which is lost is not restored. The loss goes on more and more. 
Badal ma yatahallul (Substitute of dissolution)

In classical Unani literature, the term akhlat is used for the body fluids that serve the function of nutrition, growth and repair; and produce energy for the preservation of individual and his species and also replaces the loss from dissolution. Buqrat (460BC) was the first physician who put forth the novel and rational theory, "The theory of akhlat" and propounded exquisitely that the preservation of health depends on akhlat arbah. Akhlat is a fluid substance which is the initial product of the digestion of food reaching liver. Healthy or good akhlat are those which have the capacity of becoming transformed into actual body substance; either by itself or in combination with something else and these serve the above mentioned functions. These akhlat are four in number and therefore called 'akhlat arbah' and are as follows:

- Dam (Sanguineous Humour): The most excellent of all which is of a balanced nature and exceeds the other humours in quantity.

- Balgham (Phlegm or Serous Humour): It is an imperfectly matured blood and is capable of transformation into blood whenever required.

- Safra (Bilious Humour): It is the foamy part of the blood and is less plentiful in the body than dam or balgham. It provides a diffusing quality to the blood so that it may enter readily into each tissue of the body. It also prevents the body from becoming heavy, sleepy and dull.

- Sauda (Atrabilious Humour): It thickens the blood and prevents it from flowing freely through the blood vessels. It bestows stamina, strength, density and consistency to the blood.

Till these humours remain in equilibrium, health is maintained and derangement in these qualitatively or quantitatively leads to different diseases ${ }^{2-6}$.

\section{Tabiyat}

There is a difference of opinion among Unani physicians regarding the definition of tabiat. According to the doctrine of Buqrat, tabiat is that faculty or power which safeguards the body and initiates movement and repose in it involuntarily. According to Aflatoon tabiat is that heavenly power which dominates the body in its protection. Allama Nafees noted that the basis of tabiat depends on four things - first and foremost on the temperament of the body which is the best and particular to the body, on the body constitution, on the medication nature and on the psychic movement. Allama Qarshi has said that tabiat is that quwwat which safeguards the activities of the body in which it exists.

The general opinion is that Tabiat is Quwaate Mudabbire-badan and in modern or English language, it is called nature or Physic faculty. It is a power which is a well organized system, which maintains the internal environment and safeguarding the bodily temperament, thus tabiat is nothing but the resisting force of the human body against the factors which tends to change the harmony. Perhaps Claud Bernard has gifted with the terms milieu interior and homeostasis for this internal environment of the body. Thus it is that power of the body which acts and serves in the body in different ways and brings about the movements in the organs, interconnects them and safeguards the body and thus the bodily functions are discharged normally. It also protects the body from allied threats and cures the disease.

Whenever the tabiyat becomes weak, it becomes difficult to cure the disease and for this only it is said that the tabeeb only strive to boost up the tabiyat and tabiyat is the real healer. So tabeeb is rightly called as taba'ya which means, which helps the tabiyat. Thus tabiyat is the supreme controller of all the functions of the organs and it is the tabiyat, which decides when, how, why and in which organ, the functions are to be slowed down or enhanced.

Any quwwat is not immortal, it decreases gradually with age. Tabiyat is also a quwwat that controls all quwa and their functions thus maintains homeostasis, with advancing age hararate ghareezia decreases resulting in relative baroodat in mizaj, baroodat weakens the quwa ultimately weaken the functions because quwa requires hararat for performing afaal. Tabiat also weakens with increase in baroodat. As the tabiat is supreme controller of all functions of the body whenever it becomes weak, it alters all functions of the body ${ }^{3,6}$.

\section{The dynamics of maintaining the health}

The art of maintaining the health is not the art of averting death, or of averting extraneous injuries from the body; or of securing the utmost longevity possible to the human being. It is concerned with two other things. (a) The prevention of putrefactive breakdown. (b) The safeguarding of innate moisture from too rapid dissipation, and maintaining it at such a degree of strength that the original type of constitution peculiar to the person shall not change even up to the last moment of life.

This is secured by a suitable regimen:

- One which will ensure the replacement of the innate heat and moisture which are dispersed from the body as exactly as possible.

- A regimen which will prevent any agents which would lead to a rapid tahleel (dissolution).

- One which safeguard the body from the development of putrefactive processes within it and from the influence of alien heat (whether extraneous or intrinsic) e.g. Use of Tiryaqi advia.

All bodies have not the same degree of innate moisture and innate heat. There is great diversity in regard to them. Every person has his own term of life. Under this view, the art of maintaining health consists in guiding the body to its natural span of life by paying attention to whatever things conducive thereto.

There are two faculties to be fostered by the doctor in striving for this subject:

- The Quwwate hadima (nutritive faculty), whereby that is replaced, which is constantly being lost to the bodynamely earthiness and aquosity;

- The sensitive faculty- that is the Quwwate haiwania (pulsatile faculty), which is concerned with the replacement of that which is lost to the body by breath- namely "air" and "igneity".

Therefore we may say that the essential considerations in the art of preserving the health consist in equilibrium 
between all these various concomitant factors. But there are seven matters for which special care must be expanded to ensure just proportion:

- Equilibrium of temperament.

- Selection of the articles of food and drink.

- Evacuation of effete matters.

- Safeguarding the composite.

- Maintaining the purity of air respired.

- Guarding against extraneous contingencies.

- Moderation in regard to the movements of the body and the motions of the mind which may be included sleep and wakefulness ${ }^{2,6}$.

Possible prevention and management of geriatric diseases in Unani system of medicine in present scenarios

We can prevent and manage the geriatric diseases by the following manner

- Tadabeer-e-ghiza (Dietary management)

- Ilaj-bil-tadbeer (Regimenal therapy)

- Ilaj-bil-dawa (Drug therapy) $7,8,9$

There are following diseases in which we can apply the above principles of Unani system of medicine to manage and prevent those diseases

Tadabeer-e- Ghiza: According to Unani physicians, in old age there is dominancy of Baroodat and Yaboosat, therefore Musakhkhin and Murattib diet should be advocated for elderly people. In this stage of life there is great chance to reduction of Hararate ghareezia, which is very necessary for life, therefore during old age following diet should be advised, which may be very beneficial to improve the life style of elderly people

(a) Wheat: It is a very famous cereal and commonly used in daily food, according to Unani physicians, the Mizaj of wheat is Moatadil Har. Its nutritional value is also very high and the food made by wheat are also very delicious and it produces Moatadil blood, these property of wheat may be helpful for elderly persons to provide Taskheen to restore Hararate ghareezia. Sameequl hamtah (flour of roasted wheat) is very good diet for elderly people specially when it is mixed with water and sugar, it is a Muqawwi jigar diet.

(b) Gram: The Mizaj of gram is Haar and it also a Mudir, it increases production of sperm, but raw gram may be harmful for elderly people, because it produces Riyah, therefore it should be roasted and after roasting it is beneficial for all ages.

(c) Alcohol: According to Unani physicians alcohol is harmful for liver, brain, nerves, causes tremors, convulsions, paralysis and shock, further they described that, moderate use of alcohol may be beneficial for elderly people, specially consumption of alcohol with water may expel Riyahe ghaliza from liver, stomach and corrected barid condition of stomach and liver.

(d) Sikanjabeen (Vinegar + Honey): It is a very famous diet which is described by Unani physicians, it has various effect like Qate safra, Musaffie dam, Qate balgham, Mufatteh sudad and Mudire bol etc. therefore it may be beneficial for those elderly people, who are suffering from Diabetes Mellitus, Hypertension and Hyperlipidaemia like condition, it may also ease the life of elderly persons because in elderly people there is presence of nerve weakness and dominancy of baroodat in liver and stomach.

(e) Maul asl (Barley water): The Mizaj of Maul Asl is Har yabis, therefore it may be very beneficial for elderly people specially in condition of barid amraz like paralysis and Bell's palsy, because it has effect of Munzije balgham, it also expels balgham from stomach and provided Sukhoonat to the nerve.

(f) Anjeer (Fig): The Mizaj of anjeer is Haar ratab it is a very good Mulayyan (Laxative) and its nutritional value is also very high. According to Unani physicians it provided Sukhoonat to the body, therefore it may be helpful to improving the life style of elderly people.

(g) Narjeel (coconut): The Mizaj of coconut is Haar Ratab and its nutritional value is also high, due to Haraarat and rutoobat it may be beneficial for elderly people and it is now proven that, coconut has very nutritional value and beneficial for all age group.

(h) Asl (Honey): The Mizaj of honey is Haar, due to which it may be beneficial for non diabetic elderly people, it also has Musakhkhin effect and very beneficial for Barid mizaj people, after 40 years of age everybody should advice to use one tea spoon of honey every day. Now it is proven that honey has effect of immunomodulator and improve immunity.

\section{Ilaj bit Tadbeer (Regimental therapy)}

The scope of regimenal therapy is increasing day by day, it is a branch of Unani medicine which deals with that line of treatment, in which without the use of medicine we can manage or prevent various diseases or if medicines are used it does not affect directly on the disease but it helps to remove those causative factors of diseases and corrected six essential of life e.g. Istefragh by Ishaal and Taareeque. Following regimen should be used for prevention of various diseases of elderly people e.g. diabetes mellitus, hypertension, hyperlipidaemia, other life threatening condition of elderly people and improve life style of elderly.

(a) Riyazat (Exercise): Without diet life is not possible, because diet gives us energy to perform various physiological and metabolic functions of life. According to Unani concept, the digestion of food takes place in four stages i.e. Hazme medi , Hazme kabidi, Hazme urooqee and Hazme uzwee (stomach, liver, vessels and in the cells) after that it become part of the body, but some food in each stage of digestion remain undigested which accumulate in the body as waste product, it slowly damage the body's various structure (The concept of free radicals), therefore to excrete those harmful substances from body, the need of an alternative methods to remove 
those particle from body is increased. For that purpose Unani physicians has suggested a regimen which is known as Riyazat, Ibne Nafees a famous Unani philosopher mentioned that "No alternative of Riyazat present in the tibb", further he mentioned that, Alcohol may replace the Riyazat But it has various side effects. In old age there are vast majority of free radicals present in the body; they are very harmful for human life. To overcome this unwanted situation of body an elderly people should perform Moatadil riyazat (moderate exercise) regularly because Moatadil riyazat produce Musakhkhin effect in the body of elderly people and it also expels those harmful substances from the body and it prevent various disease like hypertention, Diabetes Mellitus, osteoarthritis and enhances immunity.

(b) Dalak (Massage): It is a very old type of regimen and it is abundantly used in all age groups since child hood to strengthen the body. In elderly people Moatadil (moderate) type of dalak should be done specially on those part of the body which became weak, the dalak should be done with or without oil, but the oil should be Haar (hot by temperament) like Roghane Zaitoon, Roghane Badam and other types of Haar oil which provided Taskheen to the body of elderly people.

Ilaj bil Dawa (Drug therapy): Prevention of wabai amraz with Tiryaqi Advia is recommended in Unani system of medicine since ancient times. Tiryaq is normally advised for the prevention of toxicity (sepsis) as a prophylactic drug. Tiryaqiyat are those formulations which strengthen the Rooh in such a way that Rooh becomes able to neutralize the toxicity produced in the body. Tiryaqiyat strengthen the rooh, stimulate harartegharizia thus helps tabiyat to protect the body from harmful effects of morbid materials. Avicenna described that the persons who will use Tiryaq in healthy condition will not be affected from infectious diseases because it helps in strengthening the Rooh and maintaining the health. Ismail Jurjani describes that use of Tiryaq during epidemics; strengthens the heart, keeps the faculties strong and prevent sepsis. Jalinoos mentioned that the persons, who used Tiryaq wabai as prophylactic drug in healthy condition did not affected from infectious diseases. Apart from that, there are certain drugs like amla (Phyllanthus emblica, (Emblica officinalis), garlic (Allium sativum), ginger (Zingiber officinalis), anjeer (Ficus carica) and black cumin (Nigella sativum) which are widely used in Unani Medicine and now are proven to have anti oxidant and immunomodulator properties. Scientific studies revealed that, antioxidants drugs have definite role in the prevention of geriatric diseases.

\section{CONCLUSION}

The concept of protection of an organ, stimulation of Hararate-gharizia and augmentation of vital force of important organs is the distinguishing feature of Unani medicine. The concept aim was to maintain the vitality of organs by protecting it from untoward stimuli and strengthening it to cope with the diverse physiological climate. A number of drugs categorize to possess such effects are frequently used in children, old age and debilitating persons. Some of the drugs studied in recent years demonstrate promising effect. With life style modification and adopting various regimens and principles of Unani System of Medicine, certain Geriatric changes can be slowed down to a greater extent, while some diseases can be prevented in elderly peoples. It is important to understand that drug trials for evaluating efficacy of Unani Tibb interventions is a reductionist approach and is an inappropriate design. Instead clinical trials should evaluate the efficacy of a whole management package which may consist of drugs, diet, Ilaj- bil-tadbeer including differential diagnosis to identify the specific nature of Humoral imbalance.

\section{REFERENCES}

1. Suhami RL, Moxham J, Textbook of medicine. $4^{\text {th }}$ edition. New York: Churchill Livingstone; 2004:183-85.

2. Gruner O. Cameron. A Treatise on the Canon of Medicine of Avicenna. London: Luzac and Co; 1930:358-360.

3. Arzani Akbar. Mufarrah ul Quloob. New Delhi: Idara Kitab ul shifa; 2002: 9-10.

4. Kabeeruddin M. Kulliyate Qanoon. Lahore: Sheikh Mohd. Basheer and Sons; (YNM): 69-89.

5. Ahmad Ishtiyaq. Kulliyate Asri. New Delhi: New Public Press; (YNM): 509-14.

6. Ibn Sina. Alqanoon Fil Tib (Urdu translation by G.H. kanturi) Vol.2. New Delhi: Idara kitab ul Shifa; 2010: 5, 22.

7. Mohd Anwar. Geriatric Care in Unani System of Medicine A prophylexis, Hamdard Medicus, July- September 2004;XLVII(3):96

8. Al Razi, Kitabul Mansoori (Urdu), Published by CCRUM, Delhi, 1991 p 94, 98,119,123,184.

9. Ajmal Khan, Hazique, $1^{\text {st }}$ edition, Published by Jaseem Book Depot, New Delhi, 1983 p 385.

Cite this article as:

Malik Itrat, Zarnigar, N. Haque. Concept of aging in Unani medicine. Int. J. Res. Ayurveda Pharm. 2013;4(3):459-462 